\title{
Combined heart-liver transplant in a situs-ambiguous patient with failed Fontan physiology
}

\author{
Prashanth Vallabhajosyula, MD, MS, ${ }^{\mathrm{a}}$ Caroline Komlo, BS, ${ }^{\mathrm{a}}$ Tyler J. Wallen, DO, ${ }^{\mathrm{b}}$ Kim Olthoff, MD, ${ }^{\mathrm{a}}$ and \\ Alberto Pochettino, MD, ${ }^{\mathrm{c}}$ Philadelphia and Hershey, Pa, and Rochester, Minn
}

Combined heart-liver transplantation (CHLT) in patients with congenital heart disease (CHD) has been performed in the setting of heart-liver failure secondary to failed Fontan/single-ventricle physiology. Recently, referral of patients with failed Fontan physiology has increased at our institution. These patients now present-15 to 20 years post-Fontan palliation —with a "burned out" single ventricle with ensuing liver failure. CHLT in these patients is challenging with regard to intraoperative techniques and postoperative care. CHLT in patients with situs inversus/ambiguous can be even more complex, requiring technical modifications and complex venous and arterial reconstruction. ${ }^{1-3}$

\section{CLINICAL SUMMARY}

We report the case of 42-year-old man with situs ambiguous with successful Fontan palliation, who 20 years later, underwent sixth-time redo sternotomy CHLT with venous and arterial reconstruction requiring a period of deep hypothermic circulatory arrest.

The patient had heterotaxy syndrome (asplenia variety) with situs ambiguous with midline liver, right upper quadrant stomach and pancreatic head (dextrogastria), bilateral trilobed lungs, imbalanced complete atrioventricular canal defect with diminutive right ventricle, pulmonary atresia, common atrium receiving pulmonary venous and coronary sinus flow, left superior vena cava (SVC) with atrophic right SVC, left ventricle injected into a right-sided aortic arch with mirror image branching, separate hepatic vein confluence draining directly into the common atrium, and a leftsided inferior vena cava (IVC).

The patient had undergone right Blalock-Taussing shunt as a newborn infant, followed by Waterston shunt at age 2 years with revision at age 8 years. At age 11 years, he underwent Blalock-Taussing shunt revision by enlargement with a pericardial patch. At age 23 years, he underwent takedown of systemic-pulmonary shunts and construction

\footnotetext{
From the Department of Surgery, ${ }^{\text {a }}$ Hospital of the University of Pennsylvania, Philadelphia, Pa; Department of Surgery, ${ }^{\mathrm{b}}$ Milton S. Hershey Medical Center, Hershey, $\mathrm{Pa}$; and Department of Cardiovascular Surgery, ${ }^{\mathrm{c}}$ Mayo Clinic, Rochester, Minn. Disclosures: Authors have nothing to disclose with regard to commercial support. Received for publication Nov 13, 2012; accepted for publication Dec 18, 2012; available ahead of print Feb 4, 2013.

Address for reprints: Prashanth Vallabhajosyula, MD, MS, 6 Silverstein, 3400 Spruce St, Philadelphia, PA (E-mail: Prashanth.Vallabhajosyula@uphs.upenn.edu). J Thorac Cardiovasc Surg 2013;145:e39-41 $0022-5223 / \$ 36.00$

Copyright (c) 2013 by The American Association for Thoracic Surgery http://dx.doi.org/10.1016/j.jtcvs.2012.12.066
}

of a left-sided Glenn shunt. Fontan palliation was achieved with full septation of the common atrium with intra-atrial baffle of left-sided IVC to the right side, along with the constructed right atrial to right pulmonary artery connection (Figure 1). The patient developed sick sinus syndrome with bradycardia and atrial fibrillation 10 years later, and at age 34 years he underwent fifth-time redo sternotomy with takedown of intra-atrial baffle for bilateral Maze procedure, polytetrafluorethylene patch augmentation of Fontan conduit, and pacemaker placement.

Nineteen years later, the patient presented with worsening heart-liver failure. Echocardiography showed a dilated left atrium, moderate mitral and aortic regurgitation, and depressed ejection fraction with a dilated single ventricle. He had ammonemia, protein-losing enteropathy, portal venous hypertension, and central-to-portal bridging fibrosis detected by liver biopsy. Suitable organs became available. Through sixth-time redo sternotomy, cardiopulmonary bypass was established via cannulation of the left-sided SVC and IVC, and the distal ascending aorta. The confluence of hepatic veins was encircled. The patient was cooled, during which time the difficult dissection of the heart was completed. The lesser curve of the aortic arch could not be adequately mobilized given the previous shunt operations. The decision to perform deep hypothermic circulatory arrest was made due to the dense adhesions and loss of aortic tissue. Upon cooling to $16^{\circ} \mathrm{C}$, circulatory arrest was established, and the distal aorta was dissected taking down the site of previous shunts. This required reconstruction of the lesser curve of the aortic arch with polyethylene terephthalate, and cardiopulmonary bypass was reestablished and the patient was rewarmed to $30^{\circ} \mathrm{C}$.

A donor heart was procured to accommodate the recipient's complex anatomy (Figure 1). It was harvested with the entire donor main left and proximal right pulmonary arteries intact. The donor SVC and innominate vein were kept in continuity and the aorta was procured, including the arch vessels. The donor heart implantation proceeded as follows: the left atrial anastomosis was done first at a $45^{\circ}$ clockwise 4 rotation of the heart to accommodate the following donor IVC anastomosis to the mobilized left IVC of the recipient. Next, the pulmonary artery anastomosis was completed with the donor and recipient right pulmonary artery and left pulmonary artery connections made as 2 separate anastomoses. Given concern for SVC compression with anterior location, the donor SVC innominate vein was anastomosed to the recipient's left $\mathrm{SVC}$, and brought posterior to the aortic anastomosis. 


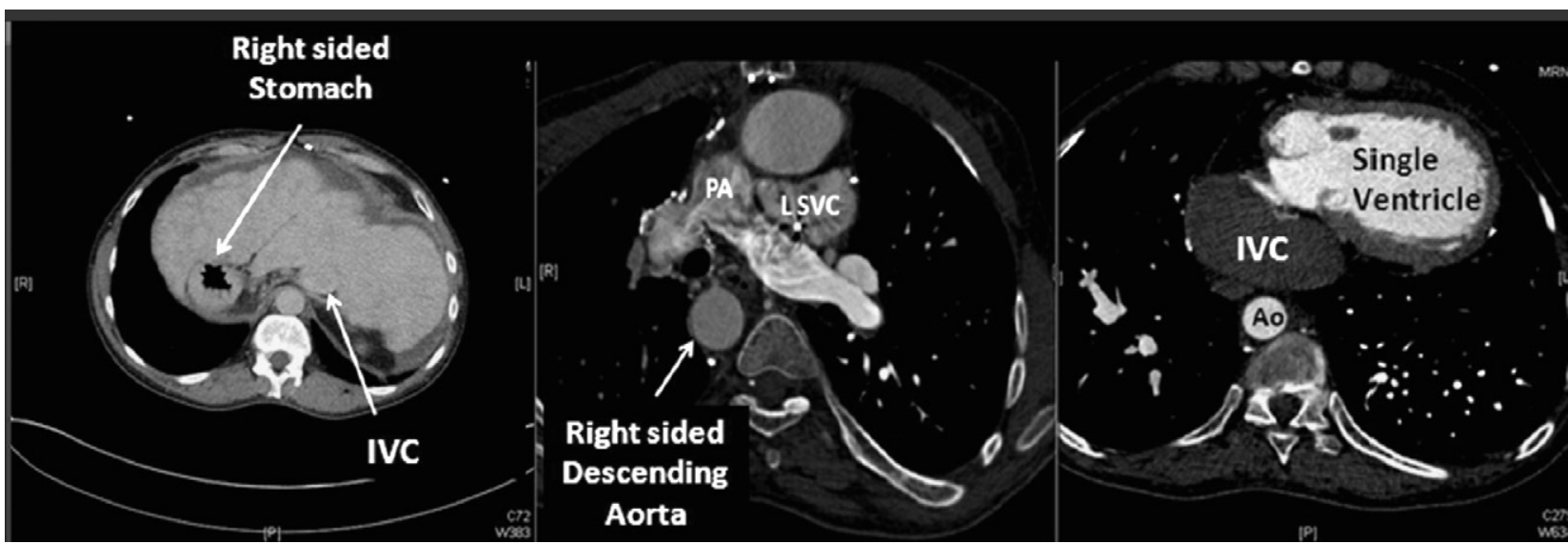

FIGURE 1. Preoperative computed tomography scan showing dextrogastria, middle liver, and the left-sided inferior vena cava (IVC) (left panel). The rightsided aortic arch, dilated single ventricle, and large left-sided IVC coming over to the extracardiac Fontan conduit and left superior vena cava ( $L S V C$ ) entering the pulmonary artery bifurcation are shown in the middle and right panels. PA, Pulmonary artery; Ao, aorta.

Finally, aortic anastomoses were completed (Figure 2). The encircled hepatic vein confluence was oversewn in the chest. The patient was weaned off cardiopulmonary bypass, protamine was administered, and hemostasis was achieved. We next proceeded to the abdominal portion of the operation. Upon mobilizing the recipient's liver and dissecting the vessels, the patient was placed on veno-venous bypass by cannulating the right atrium using the previously place cardiac bypass cannula, and percutaneously cannulating the femoral vein for systemic venous-venous bypass, followed by cannulation of the portal vein for portal-venous bypass. The liver transplant anastomoses were completed in the standard fashion, with the donor liver piggy-backed to the recipient IVC in an end-to-side fashion. The patient had a prolonged but uneventful recovery. Two years post CHLT, the patient remains in New York Heart Association functional class I, without any signs of rejection or surgical complications.

\section{DISCUSSION}

CHLT in patients with CHD and failed Fontan physiology is a difficult operation, with the diagnosis of situs inversus/ambiguous in the recipient patient adding an extra layer of technical complexity. Thorough knowledge of the patient's congenital and operative history facilitated the appropriate modifications of donor organ procurement and recipient preparation for organ explantation/implantation. The added step of aortic arch lesser curve reconstruction required hypothermic circulatory arrest. Placement of the donor SVC innominate vein to the recipient left SVC anastomosis posterior to the aortic connection prevented venous compression upon sternal closure. The $45^{\circ}$ clockwise rotation of the donor heart along with mobilization of the left-sided IVC toward the midline enabled uncompromised venous connection. Coordination between the procurement and implantation heart and liver teams was critical to the success of this technically complex operation.

To our knowledge, 1 other case report details the complexity of CHLT in patients with CHD with situs ambiguous. ${ }^{3}$ Although several differences exist in the required reconstruction during heart implantation, both the previously reported case and ours attest to the detailed planning

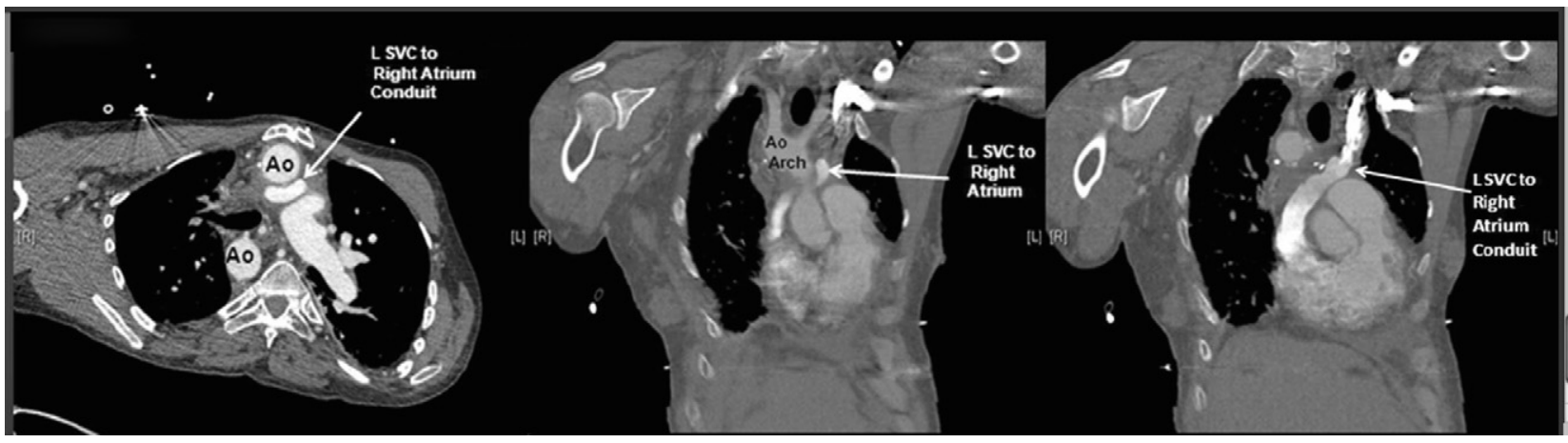

FIGURE 2. Postoperative computed tomography scan showing right-sided aortic arch (Ao Arch) with the right atrial to left-sided superior vena cava $(L S V C)$ anastomosis coursing behind the ascending aorta (Ao), anterior to the pulmonary artery. 
required to successfully implement these operations. Te and colleagues ${ }^{4}$ investigated the United Network of Organ Sharing database to look at outcomes in patients undergoing CHLT. ${ }^{5}$ Of 47 patients, $13 \%$ (6 patients) had CHD as a presenting diagnosis. Mortality in the whole group was $13 \%$ at 6 months, although the rate in patients with CHD was not reported. We recently reported our single institution experience with CHLT. Of 14 patients undergoing CHLT since 2008, 4 had failed single ventricle/Fontan physiology; 10 patients had biventricular failure. All 4 Fontan patients had protein-losing enteropathy with central-toportal bridging fibrosis on liver histology. The Fontan group had no mortality at 1year follow-up, whereas the biventricular failure group had 2 deaths $(20 \%)$. Outcome analysis suggested that CHLT in patients with single ventricle physiology can be performed safely, with equivocal early outcomes to CHLT in patients with biventricular failure.

\section{References}

1. Rubay JE, d'Udekem Y, Sluysmans T, Ponlot R, Jacquet L, de Laval MR. Orthotopic heart transplantation in situs inversus. Ann Thoracic Surgery. 1995;60:460-2.

2. Larsen RL, Eguchi JH, Mulla NF, Johnston JK, Fitts J, Kuhn MA, et al. Usefulness of cardiac transplantation in children with visceral heterotaxy (asplenic and polysplenic syndrome and single right-sided spleen with levocardia) and comparison of results with cardiac transplantation in children with dilated cardiomyopathy. Am J Cardiol. 2002;89:1275-9.

3. Tetsuya H, Bhama JK, Fontes PA, Toyoda Y. Combined heart and liver transplantation in a patient with situs ambiguous. Ann Thoracic Surgery. 2011;91:600-1.

4. Te HS, Anderson AS, Millis JM, Jeevanandam V, Jensen DM. Current state of combined heart-liver transplantation in the United States. J Heart Lung Transplant. 2008;27:753-9.

5. Vallabhajosyula P, Komlo C, Molina M, Roche L, Kim Y, Goldberg L, Pochettino A. 314 combined heart-liver transplantation (HLT) for failed single ventricle/Fontan physiology. J Heart Lung Transplant. 2012;31:S112.

\title{
Epicardial cryoablation resulting in precipitous left ventricular dysfunction
}

\author{
Steven M. Lampert, MD, ${ }^{a}$ Gregory F. Michaud, MD, ${ }^{b}$ Gregory S. Couper, MD, ${ }^{\mathrm{c}}$ and \\ Jochen D. Muehlschlegel, MD, MMSc, ${ }^{a}$ Boston, Mass
}

Video clip is available online.

We present a case of recurrent coronary vasospasm with subsequent hemodynamic collapse that occurred during epicardial cryoablation for refractory premature ventricular contractions (PVCs). The resulting hemodynamic changes and left ventricular dysfunction were successfully treated, leading to a favorable perioperative outcome.

\section{CLINICAL SUMMARY}

A 63-year-old man with a history of coronary artery disease and remote myocardial infarction presented with 1

\footnotetext{
From the Department of Anesthesiology, ${ }^{\mathrm{a}}$ Perioperative and Pain Medicine, Division of Cardiology, ${ }^{\mathrm{b}}$ and Division of Cardiac Surgery, ${ }^{\mathrm{c}}$ Brigham and Women's Hospital, Boston, Mass.

Disclosures: Authors have nothing to disclose with regard to commercial support.

Received for publication July 11, 2012; revisions received Dec 19, 2012; accepted for publication Jan 11, 2013; available ahead of print Jan 31, 2013.

Address for reprints: Jochen D. Muehlschlegel, MD, MMSc, Department of Anesthesiology, Perioperative and Pain Medicine, Brigham and Women's Hospital, 75

Francis St, Boston, MA 02115 (E-mail: jmuehlschlegel@ partners.org).

J Thorac Cardiovasc Surg 2013;145:e41-2

$0022-5223 / \$ 36.00$

Copyright (C) 2013 by The American Association for Thoracic Surgery

http://dx.doi.org/10.1016/j.jtcvs.2013.01.023
}

year of palpitations, dyspnea on exertion, and multiple syncopes. Holter monitoring demonstrated frequent PVCs. Preoperative transesophageal echocardiography (TEE) showed normal valvular function, preserved ejection fraction, and left ventricular hypertrophy without wall motion abnormalities. Although 2 separate endocardial ablation procedures temporarily terminated the premature beats, PVCs persisted and medical management ultimately failed, which prompted off-pump epicardial cryoablation of the left ventricular myocardium. Both radial arterial line and internal jugular triple lumen catheters were placed followed by a standard intravenous induction and maintenance anesthesia using isoflurane, and a TEE probe was placed for intraoperative monitoring. An isoproterenol infusion was used to augment the PVCs until a regular frequency was established. Electrophysiology studies showed that the origin of the PVCs was located on the anterobasal left ventricular epicardial surface near the bifurcation of the left main coronary artery (Figure 1). The area of interest was close to the origin of the anterior cardiac vein from the great cardiac vein. A full sternotomy was performed, the pericardium was opened, and dissection to the area of interest was uneventful. Mobilization and manipulation of the coronary arteries were performed to target the areas of interest. The line of ablations of the cryoprobe (Cardioblate CryoFlex; Medtronic ATS Medical Inc, Minneapolis, Minn) was alongside 